\title{
PENYEDIAAN TAMAN KOTA SEBAGAI RUANG TERBUKA HIJAU (RTH) DI KAWASAN KAIDIPANG KABUPATEN BOLAANG MONGONDOW UTARA
}

\author{
Abdul Mannan \\ Dosen Program Studi Teknik Arsitektur Universitas Ichsan Gorontalo
}

\begin{abstract}
Abstrak
Ruang terbuka hijau (RTH) di wilayah perkotaan memiliki fungsi yang penting diantaranya terkait aspek ekologi, sosial budaya, dan estetika. Adapun dalam penyediaannya, haruslah memenuhi kriteria ruang publik yang ideal seperti lokasi yang mudah dijangkau, nyaman, dan memberikan rasa aman bagi penggunanya. Masih kurangnya ketersediaan jumlah RTH publik khususnya hutan kota dan taman kota pada kawasan pusat kota Kaidipang sedikit banyak mempengaruhi fungsi hutan kota dan taman kota tersebut sebagai ruang terbuka hijau (RTH) publik. Tujuan dari penelitian ini adalah untuk mengkaji fungsi dan kriteria penyediaan sebagai ruang terbuka hijau (RTH) publik pada hutan kota dan taman kota serta memberikan rekomendasi dalam peningkatan kualitas hutan kota dan taman kota sebagai ruang terbuka hijau (RTH). Jenis pendekatan yang dilakukan dalam penelitian ini adalah pendekatan kuantitatif. Sementara itu, proses analisis data yang dilakukan membutuhkan fakta yang berhubungan dengan fenomena aktual di hutan kota dan taman kota sebagai RTH publik kawasan pusat kota Kaidipang. Metode analisis yang digunakan dalam penelitian ini adalah analisis deskriptif dan distribusi frekuensi. Berdasarkan hasil analisis tersebut, didapatkan hasil bahwa ruang terbuka hijau (RTH) publik yang cocok digunakan adalah RTH publik yang berfungsi sebagai peneduh dan paru-paru kota, yang dapat menjadi pusat interaksi dan komunikasi masyarakat serta sarana rekreasi. Selain itu, masyarakat memilih RTH publik yang dapat memberikan kenyamanan misalnya dengan menyediakan fasilitas yang memadai.
\end{abstract}

Kata kunci: RTH Publik, Hutan Kota, Taman Kota

\begin{abstract}
Green open space in urban areas has an important function, including related aspects of ecology, social culture, and aesthetics. As for the provision, it must meet the criteria of an ideal public space such as a location that is easy to reach, comfortable, and provides a sense of security for its users. There is still a lack of availability of green open space, especially urban forests and city parks in the downtown area of Kaidipang, which affects the function of the urban forests and city parks as a green open space.

The purpose of this study was to examine the functions and criteria for the provision of green open space in urban forests and city parks and provide recommendations for improving the quality of urban forests and city parks as green open spaces. The type of approach taken in this study is a quantitative approach. Meanwhile, the process of data analysis requires facts relating to the actual phenomenon in urban forests and city parks as a public green space in the downtown area of Kaidipang. The analytical method used in this study is descriptive analysis and frequency distribution.

Based on the results of the analysis, it was found that green open space that were suitable to the area was green open space that functioned as shade and lungs of the city, which could be the center of community interactions and communications as well as recreational facilities. In addition, people choose green open space that can provide comfort, for example by providing adequate facilities.
\end{abstract}

\section{Keywords: Green Open Space ; Urban Forests ; City Park}

\section{PENDAHULUAN}

Kegiatan pembangunan pada dasarnya merupakan upaya untuk meningkatkan taraf hidup manusia dengan jalan memanfaatkan sumber daya alam yang terdapat di sekitar lingkungan hidupnya. Untuk itu dari sejak semula, sepanjang perjalanan sejarah manusia itu sendiri, berbagai ikhtiar telah dilakukan oleh manusia untuk dapat mendayagunakan berbagai sumber kekayaan alam, sehingga beranekaragam hasilnya telah pula dapat dinikmati dan dirasakan. Karena itu pada hakekatnya pembangunan ini jelas merupakan campur tangan manusia terhadap hubungan timbal balik antara dirinya dengan lingkungan hidupnya dalam upaya memanfaatkan sumber daya alam bagi kepentingannya.

Dalam kegiatan pembangunan ini campur tangan manusia diperkuat pula oleh kemampuannya untuk mengembangkan ilmu dan teknologi. Sehingga pada suatu taraf perkembangan sejarah budayanya, manusia pernah menganggap dirinya mampu untuk menguasai alam dan lingkungan hidupnya, selama sumber daya alam masih dapat digali, serta selama ilmu dan teknologi masih dapat dikembangkan.

Sungguh pun demikian realita mutakhir menunjukkan bahwa perkembangan sejarah manusia ini terutama di perkotaan telah membuat lingkungan hidup dihantui oleh tekanan penduduk yang semakin 
berat, kemiskinan yang tak kunjung terhapuskan, pencemaran lingkungan yang semakin gawat, jumlah persediaan air yang tidak seimbang dengan permintaan akan air bersih dan sehat, luas tanah produktif dan lahan terbuka kian berkurang, kemampuan alam melestarikan kelangsungan hidup berbagai flora dan fauna secara alamiah semakin menurun.

Kuantitas dan kualitas ruang terbuka publik terutama Ruang Terbuka Hijau (RTH) saat ini mengalami penurunan yang sangat signifikan dan mengakibatkan penurunan kualitas lingkungan hidup yang berdampak keberbagai sendi kehidupan perkotaan antara lain sering terjadinya banjir, peningkatan pencemaran udara, dan menurunnya produktivitas masyarakat akibat terbatasnya ruang yang tersedia untuk interaksi sosial.

\section{PEMBAHASAN}

\subsection{Ruang Terbuka Hijau (RTH)}

Idealnya sebuah kota memiliki RTH minimal $30 \%$ dari total luas kota, mengacu pada KTT Bumi di Rio de Janeiro, Brazil (1992), dan dipertegas pada KTT Johannesburg, Afrika Selatan (2002). Bagi wilayah dengan ciri kekotaan kuat, senantiasa akan dihadapkan pada kondisi semakin menurunnya kualitas dan kuantitas RTH yang dapat dialokasikan, karena desakan pertumbuhan sarana dan prasarana kota, sebagai konsekuensi dari dinamika meningkatnya kebutuhan warga kota akan wadah kegiatan. Manfaat yang diharapkan dari perencanaan RTH di kawasan perkotaan, adalah. a. Sarana untuk mencerminkan identitas (citra) daerah; b. Sarana penelitian, pendidikan, dan penyuluhan; c. Sarana rekreasi aktif dan rekreasi pasif, serta interaksi sosial; d. Meningkatkan nilai ekonomis lahan perkotaan; e. Menumbuhkan rasa bangga dan meningkatkan prestise daerah; f. Sarana aktivitas sosial bagi anak-anak, remaja, dewasa dan manula; g. Sarana ruang evakuasi untuk keadaan darurat; $h$. Memperbaiki iklim mikro; dan i. Meningkatkan cadangan oksigen di perkotaan

Ruang terbuka, Ruang Terbuka Hijau (RTH), ruang publik (public spaces) mempunyai pengertian yang hampir sama. Secara teoritis yang dimaksud dengan ruang terbuka adalah: ruang yang berfungsi sebagai wadah (container) untuk kehidupan manusia, baik secara individu maupun berkelompok, serta wadah makhluk lainnya untuk hidup dan berkembang secara berkelanjutan.

Ruang terbuka adalah ruang yang bisa diakses oleh masyarakat baik secara langsung dalam kurun waktu terbatas maupun secara tidak langsung dalam kurun waktu tidak tertentu. Ruang terbuka itu sendiri bisa berbentuk jalan, trotoar, ruang terbuka hijau seperti taman kota, hutan dan sebagainya (Utomo dalam Haryanti, 2008). Ruang Terbuka Hijau kota adalah bagian dari ruang-ruang terbuka suatu wilayah perkotaan yang diisi oleh tumbuhan, tanaman, dan vegetasi guna mendukung manfaat langsung atau tidak langsung yang dihasilkan oleh RTH dalam kota tersebut yaitu keamanan, kenyamanan, kesejahteraan, dan keindahan wilayah perkotaan tersebut (Dep. Pekerjaan Umum, 2008).

Berdasarkan bobot kealamiannya, bentuk RTH dapat diklasifikasi menjadi (a) bentuk RTH alami (habitat liar/alami, kawasan lindung) dan (b) bentuk RTH non alami atau RTH binaan (pertanian kota, pertamanan kota, lapangan olah raga, pemakaman; berdasarkan sifat dan karakter ekologisnya diklasifikasi menjadi (a) bentuk RTH kawasan (areal), dan (b) bentuk RTH jalur (koridor); berdasarkan penggunaan lahan atau kawasan fungsionalnya diklasifikasi menjadi (a) RTH kawasan perdagangan, (b) RTH kawasan perindustrian, (c) RTH kawasan permukiman, (d) RTH kawasan pertanian, dan (e) RTH kawasankawasan khusus, seperti pemakaman, olah raga, alamiah (Dep. Pekerjaan Umum, 2008).

Berdasarkan status kepemilikan, RTH diklasifikasikan menjadi RTH publik, yaitu RTH yang berlokasi pada lahan-lahan publik atau lahan yang dimiliki oleh pemerintah dan RTH privat atau non publik, yaitu RTH yang berlokasi pada lahanlahan milik pribadi (Dep. Pekerjaan Umum, 2008). Dalam skala lingkungan permukiman, sesuai dengan Permen PU mempersyaratkan tersedianya ruang terbuka hijau dalam secara berjenjang sesuai tingkat kewilayahan, tingkat Rukun Tetangga (RT), Rukun Warga (RW), maupun tingkat kota. Pekarangan, atau halaman rumah, luasnya secara umum diatur dalam rencana $\mathrm{KDH}$ dengan ideal besarannya $\mathrm{KDH}$ adalah $30 \%$, sehingga $30 \%$ dari luas kapling merupakan RTH yang memiliki fungsi estetis sebagai pelembut bangunan, fungsi ekologis sebagai peneduh, menjamin peresapan air hujan, mencegah erosi percik, pengubah iklim mikro, penyerap timbal, $\mathrm{CO} 2$, penyaring debu dan kebisingan, penahan angin serta mengurangi silau matahari.

\begin{tabular}{|c|c|c|c|c|c|c|c|}
\hline Nos & Jente Sxrsins & $\begin{array}{l}\text { ani } \\
\text { posdk } \\
\text { gimal }\end{array}$ & Lakgere & 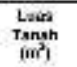 & 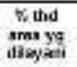 & $\begin{array}{c}\text { Rodiles } \\
\text { shonatulase }\end{array}$ & 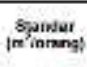 \\
\hline+ & 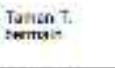 & 250 & 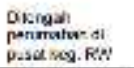 & $2 s$ & 2 & ossm & 1 \\
\hline 3 & 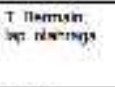 & $3.5 \mathrm{~m}$ & 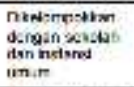 & 1778 & $\tan$ & 5150 & 6.5 \\
\hline 3 & 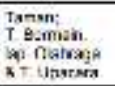 & $\sin n=5$ & 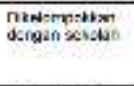 & 9050 & anzs & $\cdot$ & 63 \\
\hline 4 & 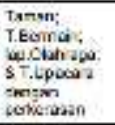 & $170 \mathrm{tan}$ & 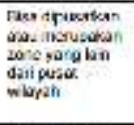 & $24 \mathrm{mot}$ & 2410 & 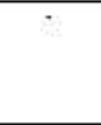 & 67 \\
\hline ¿ & 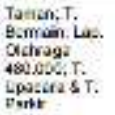 & $4 \pm 0.02$ & 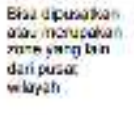 & $124: 200$ & 083 & - & 0.9 \\
\hline$n$ & Ioturt & - & $\mathrm{Nm} \times \mathrm{n}$ & . & - & -. & in \\
\hline
\end{tabular}

Dalam skala Rukun Tetangga (RT) perlu RTH yang ditujukan untuk melayani penduduk dalam lingkup 1 (satu) RT, khususnya untuk 
melayani kegiatan sosial di lingkungan RT tersebut. Luas taman ini adalah minimal $1 \mathrm{~m} 2$ per penduduk $\mathrm{RT}$, dengan luas minimal $250 \mathrm{~m} 2$. Lokasi taman berada pada radius kurang dari $300 \mathrm{~m}$ dari rumahrumah penduduk yang dilayani (Dep. Pekerjaan Umum, 2008). Dalam skala Rukun Warga (RW) dapat disediakan RTH untuk melayani penduduk satu RW, khususnya kegiatan remaja, kegiatan olahraga masyarakat, serta kegiatan masyarakat lainnya di lingkungan RW tersebut. Luas taman ini minimal $0,5 \mathrm{~m} 2$ per penduduk $\mathrm{RW}$, dengan luas minimal $1.250 \mathrm{~m} 2$. Lokasi taman berada pada radius kurang dari $1000 \mathrm{~m}$ dari rumah-rumah penduduk yang dilayaninya. Sementara untuk RTH kelurahan dapat disediakan dalam bentuk taman yang ditujukan untuk melayani penduduk satu kelurahan. Luas taman ini minimal $0,30 \mathrm{~m} 2$ per penduduk kelurahan, dengan luas minimal taman $9.000 \mathrm{~m} 2$. RTH kecamatan dapat disediakan dalam bentuk taman yang ditujukan untuk melayani penduduk satu kecamatan. Luas taman ini minimal $0,2 \mathrm{~m} 2$ per penduduk kecamatan, dengan luas taman minimal $24.000 \mathrm{~m} 2$.

Selain standar tersebut di atas, kebutuhan RTH secara umum dapat diperhitungkan berdasar Undang-Undang Tata Ruang Nomor 26 Tahun 2007, yang mensyaratkan luas RTH minimal $30 \%$ dari total wilayah kota dengan proporsi RTH berdasarkan kepemilikan adalah $20 \%$ RTH milik publik dan $10 \%$ RTH milik privat. Sementara berdasarkan pada Peraturan Pekerjaan Umum Nomor 05/PRT/M/2008 tentang Pedoman Penyediaan dan Pemanfaatan RTH di Kawasan Perkotaan, luas ruang terbuka pada kawasan permukiman diperoleh faktor pengali sebesar yaitu $20 \mathrm{~m} 2$ / penduduk. Secara kualitas, RTH perlu dibangun dan dikembangkan untuk memenuhi beberapa kebutuhan dasar penghuninya. Faktor-faktor pertimbangan itu mencakup pertimbangan: a) fisik atau dasar eksistensi lingkungan dengan membuat bentukbentuk geografis sesuai geotopograsinya; b) sosial untuk medorong penghuninya bersosialisasi; c) ekonomi, untuk memberi peluang mengembangkan sumber produk yang bisa dijual (misal : bahan makanan berupa : bunga, buah, dedaunan / sayur mayur, bahkan untuk dipanen umbi dan atau akarnya; d) budaya, sebagai ruang untuk mengekspresikan senibudaya masyarakat, serta e) kebutuhan akan terlayaninya hak-hak manusia (penduduk) untuk mendapatkan lingkungan yang aman (termasuk dari segi pentingnya kesehatan), nyaman, indah dan lestari yaitu fungsional dan estetis.

\subsection{Metodelogi}

Kajian dilakukan di Kota Kaidipang Bolaang Mongondow Utara, dengan pendekatan induktif untuk memberi makna kepada data hasil observasi dalam bentuk generalisasi empiris. Pendekatan induktif dipakai dalam penelitian kualitatif, yaitu penelitian yang memanfaatkan paradigma penelitian interpretatif yang bertujuan membangun makna berdasarkan kepada data-data lapangan (Moleong, 2001). Data dikumpulkan dengan berbagia teknik pengumpulan data mencakup observasi, pengamatan, dan pengukuran. Metode analisis dilakukan secara kualitatif deskriptif untuk menggambarkan peristiwa dan fenomena yang terjadi di wilayah studi. Sedangkan metode kualitatif rasionalistik diimplementasikan pada proses analisis dengan penekanan yang terletak pada ketajaman dan kepekaan berpikir peneliti dalam menganalisis suatu masalah atau kecenderungan yang terjadi di lapangan.

\subsection{Hasil Pembahasan}

Sebagaimana telah diatur dalam Permen PU No.5 Tahun 2008, dengan Luas Wilayah Kaidipang adalah 85,09 $\mathrm{Km} 2$. Maka $30 \%$ dari 85,09 Km2 (8.509 Ha) adalah 25,527 Km2 (2.552 Ha). Lingkub ruang Kawasan Perkotaan BWP Kaidipang berdasarkan aspek administrasi dengan luas kurang lebih 1.486,591 Ha. Maka 30\% dari 1.486,591 Ha adalah 445,977Ha. Untuk luas RTH di Kaidipang existing dapat dihitung sebagai berikut.

Tabel.1 Luas RTH Kota Kaidipang

\begin{tabular}{|c|c|}
\hline I UAS HITIAN & $\begin{array}{l}\text { WAS } \\
\text { (Ha) }\end{array}$ \\
\hline II.lial Kola & 370,19 \\
\hline I aman Kota & 7.919 \\
\hline Pẹthilkilrtesti & 2,32 \\
\hline JUMLAII & 381,2 \\
\hline
\end{tabular}

Tabel.2. Luas RTH Non Hutan Kota Kaidipang

\begin{tabular}{|c|c|}
\hline LAILN NON IIUTAN & $\begin{array}{l}\text { LUAS } \\
\text { (Ha) }\end{array}$ \\
\hline Kawasan Pctenian dan Rerkcbunan & 430,00 \\
\hline Zona sempodan suagai & 5,21 \\
\hline Zona Sempadan Pantai/Mangrove & 70,71 \\
\hline Zona Cagar Budaya/Situs Budayo & 3,17 \\
\hline JUMLNII & 510.02 \\
\hline
\end{tabular}

Dari kedua tabel diatas, dapatlah disimpulkan total luas RTH di Kaidipang adalah sebagai berikut :

Tabel.3 Luas RTH Kota Kaidipang

\begin{tabular}{|c|c|}
\hline Kawasail & Luas (Ild) \\
\hline Kavasen Hutan Kotn & : \\
\hline Kanasani Latiani Pkxi l lulani & 510,02 \\
\hline TIMIAH & $\mathrm{H} I, \mathrm{DO}$ \\
\hline
\end{tabular}

Dari Chart diatas, dapat diuraikan sebagai berikut.

1. Bahwa Luas Kawasan Hutan kota $(25,64 \%)$ dan Luas Kawasan Non Hutan (34,31\%) diperhitungkan sebagai Kawasan RTH dengan potensi kehilangan RTH rendah. Jika 
diperhitungkan secara keseluruhan, maka kondisi luas RTH di Kaidipang adalah 59,95\%. Kawasan ini akan menjadi kawasan pendukung Kawasan Lain serta merupakan kawasan cadangan RTH Kaidipang.

2. Bahwa Kawasan lain merupakan kawasan potensial berkembang menjadi kawasan perkotaan dengan potensi kehilangan RTH tinggi, dibanding kawasan Hutan dan Lahan Non Hutan dengan luas 595,371 Ha atau sekitar $(40,05 \%)$.

3. Asumsi perhitungan lahan terbangun yang ada di Kaidipang berdasarkan jumlah penduduk adalah:

- Jumlah penduduk : 13.126 jiwa

- Kebutuhan Ruang : $15 \mathrm{~m} 2 /$ jiwa

- Kebutuhan sirkulasi : 30\% kebutuhan ruang

Maka, Luas Lahan Terbangun yang ada sekarang adalah :

Luas Kawasan Terbangun $=13.126 \times 15 \mathrm{~m} 2$

$$
=196.890 \mathrm{~m} 2
$$$$
=19,69 \mathrm{Ha}
$$

Sirkulasi $(30 \%)$

$$
=19,69 \mathrm{Ha} \times 30 \%
$$$$
=5,91 \mathrm{Ha}
$$

Total Ruang Terbangun $=19,69 \mathrm{Ha}+5,91 \mathrm{Ha}$

$$
=25,6 \text { Ha }
$$

Dari angka tersebut maka Luas Lahan Terbangun adalah 4,3 \% dari Luas Kawasan Lain 595,37 Ha. Kondisi ini merupakan kondisi yang baik, namun bukan tidak mungkin dalam 20-25 tahun ke depan akan terjadi perubahan yang signifikan jika tidak segera dilakukan perencanaan, penataan, pengelolaan dan pengendalian terhadap luasan RTH di Kaidipang.

\section{a. Penentuan Lokasi Perencanaan Kaidipang}

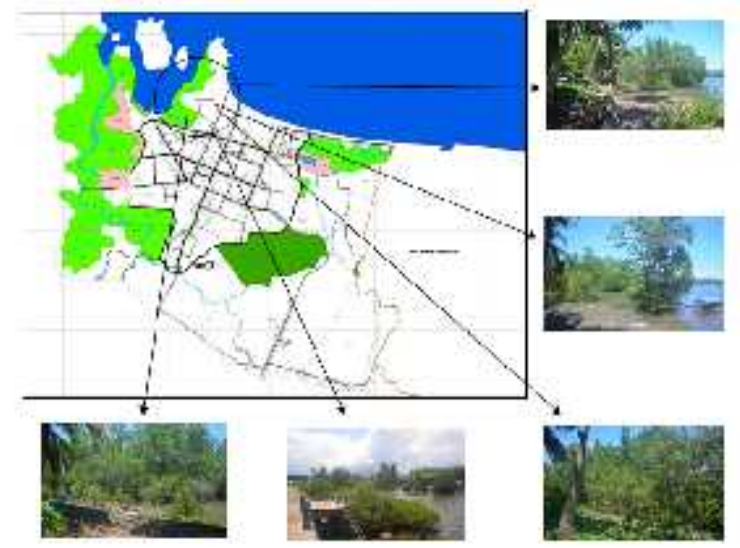

Gambar. 1 Lokasi Labuang

Beberapa alternatif pemilihan lokasi yang dapat dijadikan patokan pemilihan lokasi pembangunan RTH Kecamatan. Berikut ini alternatif lokasi yang dapat dibangun beserta penilaiannya. Lokasi pertama Labuang dekat pusat kota, tidak berada di lokasi padat penduduk, kurang memiliki nilai investasi dan ekonomi, kurang memiliki daya tarik terhadap kawasan sekitar, karakteristik lokasi tidak layak dibangun RTH, memiliki syarat luas minimum, pembangunan membutuhkan biaya besar, pembangunan membutuhkan waktu lama.

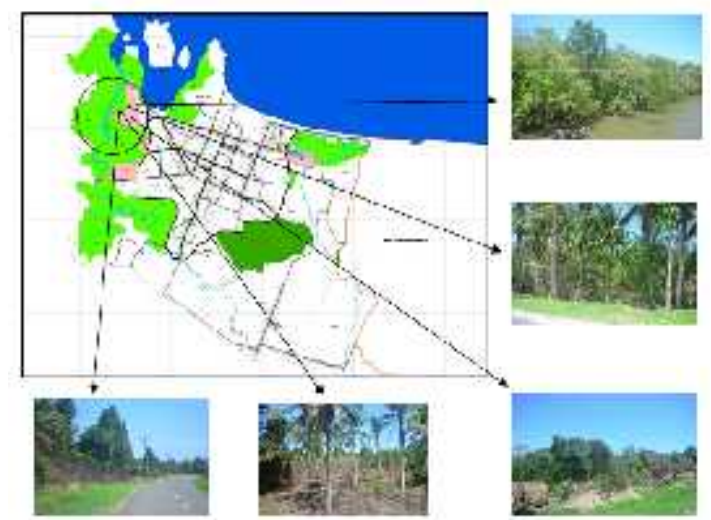

Gambar. 2 Lokasi Inomunga

Lokasi kedua Inomunga tidak dekat pusat kota, tidak berada di lokasi padat penduduk, kurang memiliki nilai investasi dan ekonomi, kurang memiliki daya tarik terhadap kawasan sekitar, karakteristik lokasi tidak layak dibangun RTH, memiliki syarat luas minimum, pembangunan membutuhkan biaya besar, pembangunan membutuhkan waktu lama.

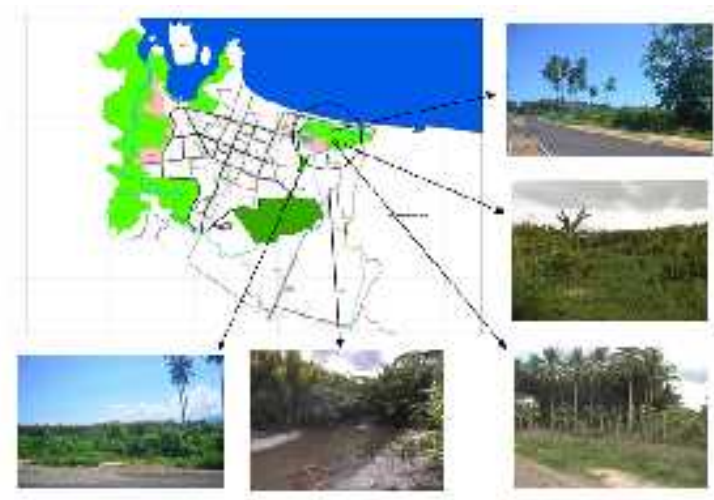

Gambar. 3 Lokasi Kuala

Lokasi ketiga di Kuala dekat pusat kota, tidak berada di lokasi padat penduduk, memiliki nilai investasi dan ekonomi, memiliki daya tarik terhadap kawasan sekitar, karakteristik lokasi layak dibangun RTH, memiliki syarat luas minimum, pembangunan membutuhkan biaya besar, pembangunan membutuhkan waktu lama.

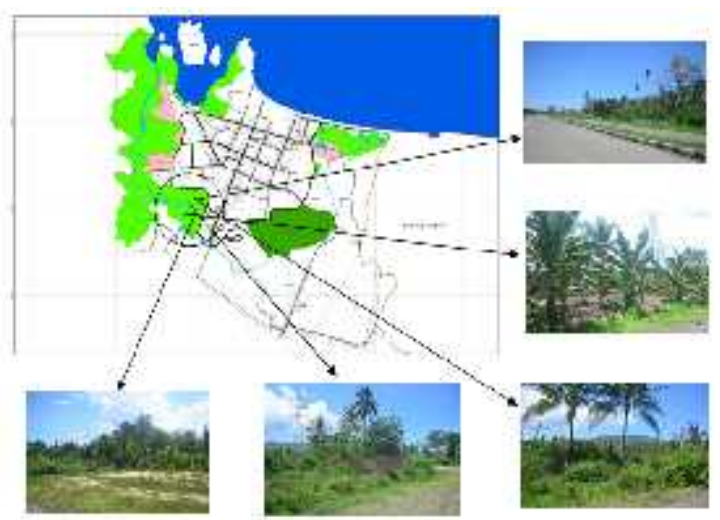

Gambar. 4 Lokasi Boroko 
Lokasi keempat di Boroko dekat pusat kota, tidak berada di lokasi padat penduduk, memiliki nilai investasi dan ekonomi, memiliki daya tarik terhadap kawasan sekitar, karakteristik lokasi tidak layak dibangun RTH, memiliki syarat luas minimum, pembangunan membutuhkan biaya besar, pembangunan membutuhkan waktu lama.

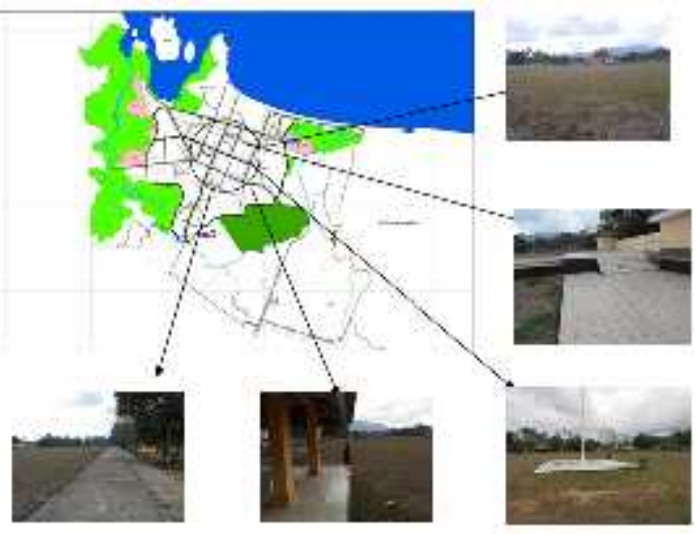

Gambar. 5 Lokasi Lapangan Kembar Boroko

Lokasi Kelima di Lapangan Kembar Boroko berada di pusat kota, berada di lokasi padat penduduk, memiliki nilai investasi dan ekonomi, memiliki daya tarik terhadap kawasan sekitar, karakteristik lokasi layak dibangun RTH, memiliki syarat luas minimum, pembangunan tidak membutuhkan biaya besar, pembangunan tidak membutuhkan waktu lama.

Tabel.4 Penilaian RTH Percontohan Kaidipang

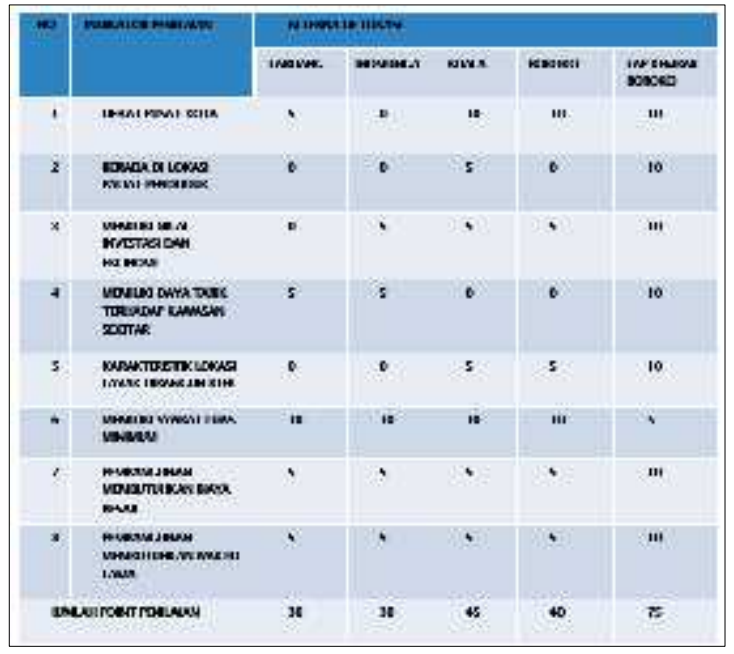

Dari hasil tabel diatas, dapatlah disimpulkan bahwa secara berurutan lokasi dengan nilai tertingi hingga terendah adalah sebagai berikut :
1. Labuang
2. Inomunga
30 Point
3. Kuala
30 point
4. Boroko
45 Point
40 Point
5. Lapangan Kembar Boroko 75 Point

Dari hasil ini maka yang layak mendapat dan prioritas sebagai Kawasan RTH Percontohan yang akan dibangun adalah Lapangan Kembar Boroko sebagai RTH Taman Kota di Kaidipang.
Kawasan ini lebih memiliki nilai ekologis, ekonomis dan sosial kemasyarakatan bagi kawasan disekitarnya dibanding lokasi yang lain. Kawasan ini lebih dibutuhkan untuk memperbaiki kondisi lingkungan disekitarnya karena kawasan ini berada di kawasan padat penduduk, perdagangan, pusat pemerintahan dan pusat kabupaten.

Selain itu, karakteristik lokasi di Lapangan Kembar Boroko memungkinkan untuk dibangun RTH Taman Kota walaupun luasan kawasan ini tidak mencapai stándar minimum RTH Kecamatan. Tentunya dengan luasan yang ini akan menekan biaya dan lama pembangunan. Efisiensi ini tentunya akan dapat mewujudkan RTH taman kota dalam waktu lebih pendek dan kawasan RTH ini akan lebih cepat berfungsi dan menjalankan tugasnya sebagai sarana ekologis, ekonomis dan sosial kemasyarakatan.

\section{b. Desain RTH Kaidipang dan Bolangitang Barat}

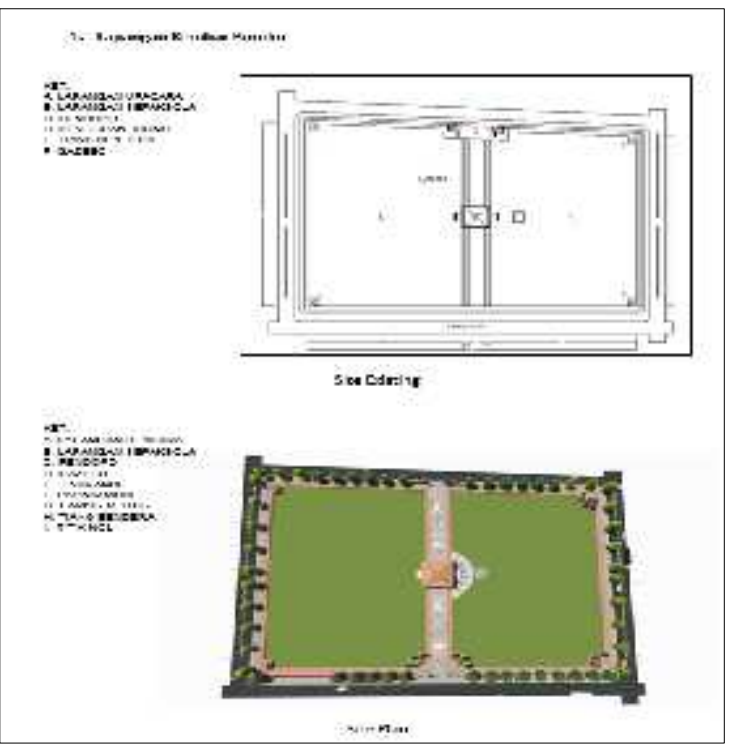

Gambar. 6 Siteplan
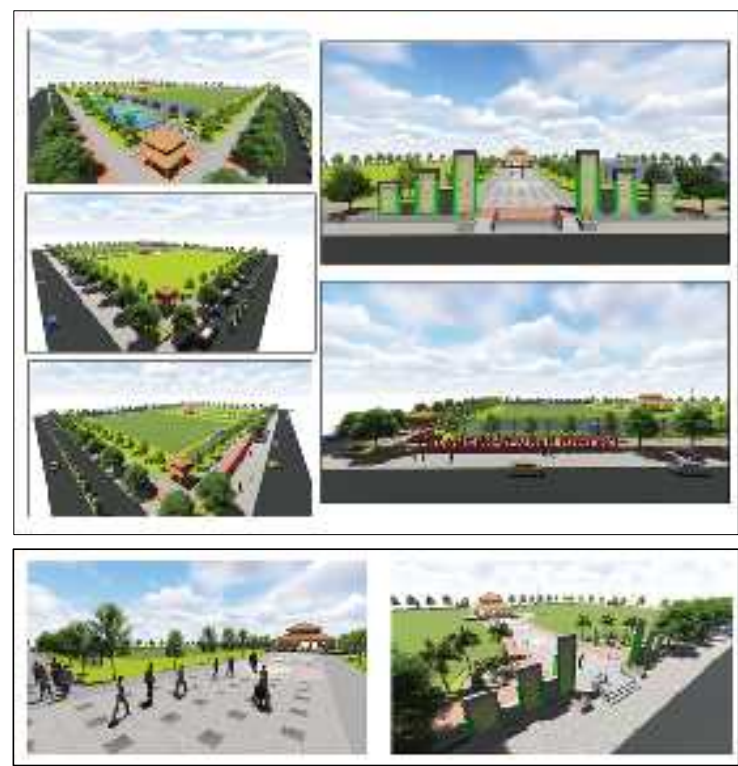


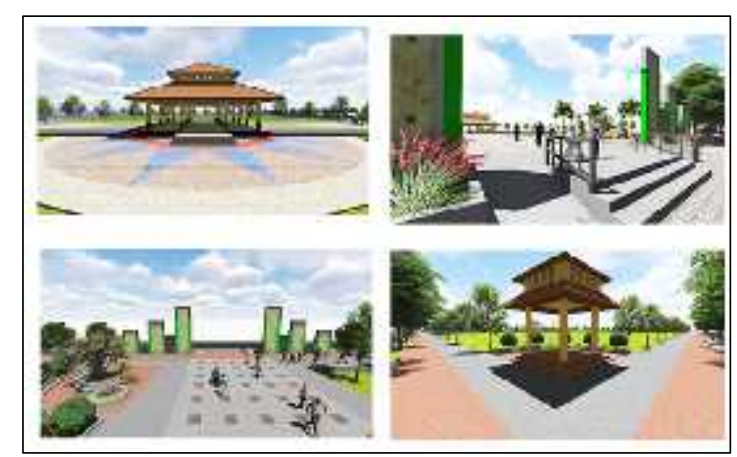

Gambar. 7 Perspektif kawasan

\section{KESIMPULAN}

Dalam pembahasan ini, terlihat bahwa Ruang Terbuka di Ibukota Kaidipang secara keseluruhan wilayah masih jauh dari ambang batas minimum untuk syarat besaran luas kawasan Ruang Terbuka Hijau. Dan beberapa hal yang menjadi perhatian antara lain bahwa Kawasan Ibukota Kaidipang belum memiliki Rencana Tindak Penataan Ruang Terbuka Hijau. Hal inilah yang menyebabkan kondisi penataan RTH di kawasan ini belum optimal. Selain itu, kawasan ini memiliki beberapa potensi yang berhubungan dengan kawasan yang dapat diubah dan ditata menjadi kawasan RTH yang memiliki nilai ekologis sekaligus nilai investasi bagi kawasan ini.

Selaku peneliti, kami sangat berharap bahwa kondisi Ruang Terbuka hijau yang memiliki fungsi paling utama sebagai kawasan yang berfungsi ekologis dapat terus dipantau dan diperhatikan. Selain itu, dengan luas RTH yang masih cukup besar dapat memudahkan pemerintah untuk melakukan penataan sejak dini agar di masa mendatang akan lebih mudah mengatasi permasalahan yang berhubungan dengan pencemaran lingkungan atau perubahan kualitas lingkungan.

Segala upaya yang berhubungan dengan sosialisasi sehubungan dengan Ruang Terbuka Hijau terus digalakkan agar dapat memberikan pemahaman dan pengertian yang baik dan tepat kepada masyarakat tentang pentingnya RTH bagi lingkungan hidup mereka. Keseriusan pemerintah dalam memikirkan, menata, mengelola, mengendalikan pelaksanaan RTH di kawasan ini menjadi hal penting untuk kemajuan dan peningkatan nilai lingkungan kawasan.

\section{DAFTAR PUSTAKA}

Djoko Sujarto dan Eko Budiharjo. Kota Berkelanjutan. Bandung: Penerbit Alumni, 1999.

Kania D. Menciptakan Kota Hijau. Bandung, Penerbit. Titian Ilmu, 2013

Mohammad Danisworo. "Arsitektur dan Perancangan Ruang Kota." Makalah Seminar Nasional. Surakarta : Universitas Sebelas Maret. 1996.
Menteri Pekerjaan Umum Republik Indonesia.. Peraturan Menteri Pekerjaan Umum Nomor 05/PRT/M/2008 tentang Pedoman Penyediaan dan Pemanfaatan Ruang Terbuka Hijau di Kawasan Perkotaan. 2008.

Peraturan Menteri Dalam Negeri Nomor 1 tahun 2007 Tentang Penataan Ruang Terbuka Hijau Kawasan Perkotaan.2007. Penataan Ruang, 